\title{
Reliability of individual differences between garter snakes (Thamnophis radix) during repeated exposures to an open field
}

\author{
DAVID CHISZAR and TERRENCE CARTER \\ University of Colorado, Boulder, Colorado 80302
}

\begin{abstract}
Eight garter snakes (Thamnophis radix) were observed during 10 daily 10-min sessions in an open field, and minute-by-minute records were kept of the frequency of tongue flicking and square traversing. The behavior of the snakes indicated that they were exploring the apparatus, and considerable individual differences were evidenced in both dependent variables. Correlational analyses compared the daily pattern of individual differences for each measure with the patterns on each other day; individual differences in each measure were found to be reliable. An interpretation of tongue flick rate is offered which suggests that this behavior may represent either an index of obligatory information gathering made necessary by a need for stimulus redundancy or an index of information processing capacity.
\end{abstract}

Aside from the role of the tongue-Jacobsen's organ system of snakes in detecting chemical cues arising from potential mates (Noble, 1937) or food (Burghardt, 1966, $1967 \mathrm{a}, \mathrm{b})$-the system is also employed during exploration of new environments (Carr, 1934) or new inanimate stimuli in otherwise familiar surroundings. However, nothing is known about variables which might influence the rate of activation of this system (as measured by the rate of tongue flicking) during exploration. Do some stimuli elicit more exploration than others? Are some individual snakes more likely to investigate objects than others? The present study was designed to answer the second question by measuring the tongue flick rate of several snakes during daily sessions in an open field.

\section{METHOD}

\section{Subjects and Maintenance Conditions}

Eight snakes ( $\overline{\mathrm{X}}$ length, snout to tip of tail, $=51.4 \mathrm{~cm}, \mathrm{SD}=$ 5.2; $\bar{X}$ weight $=43.4 \mathrm{~g}, \mathrm{SD}=12.7$ ) from a single litter served as subjects. The animals were housed in terraria containing rocks, sand, and water. Room temperature averaged $23 \pm 1^{\circ} \mathrm{C}$; relative humidity averaged $32 \%-42 \%$. The laboratory light cycle ran from 0800 to 1800 . All subjects had been maintained under these conditions for at least 2 months before serving in the present experiment. Animals were offered freshly thawed ocean perch once weekly, and all of them accepted this food; the average amount consumed in a feeding session was about $2 \mathrm{~cm}^{3}$.

\section{Apparatus and Procedure}

The open field was a $105 \times 105 \mathrm{~cm}$ plywood box with $105-\mathrm{cm}$ walls. The floor was marked off into $4915-\mathrm{cm}$ squares with thin lines of flat black paint. On each of 10 days, each snake was placed into the center of the apparatus and allowed to wander freely for $10 \mathrm{~min}$. At the end of each minute, the number of tongue flicks and the number of squares entered by the head were recorded. The floor was cleaned at the end of each day. No objects of any kind were placed in the box, and food was never

This paper is sponsored by David $R$. Thomas who takes full editorial responsibility for its contents. presented to animals while there were in the apparatus. Hence, the rates of tongue flicking and square traversing probably represent exploration of the floor, walls, and corners of the box as opposed to objects or food odors within it. Daily trials were always administered between 1000 and $1200 \mathrm{~h}$.

\section{RESULTS}

The overall mean rate of tongue flicking in the open field was $12.8 / \mathrm{min}$, the mean rate of square traversing was $2.7 / \mathrm{min}$, and the correlation between these measures was high. To quantify this latter point, the minute-by-minute records of tongue flicking and square traversing on all 10 days were correlated for each snake. The Pearson rs and $r^{2} s$ are shown in Table 1, where it can be seen that significant positive associations occurred in all snakes. Accordingly, when a snake is moving rapidly, it is tongue flicking at a high rate and when it is still or moving slowly, the rate of tongue flicking is considerably reduced. It seems most reasonable to interpret these data as indicating that movement and tongue flicking are mutually supportive systems, both of which are activated by significant changes in the stimulus milieu or by being thrust into a novel stimulus context.

Table 1

Pearson Product-Moment Correlation Coefficients Relating Tongue-Flick Rate and Square Traversing in Eight Garter Snakes*

\begin{tabular}{ccc}
\hline Snake & $\mathrm{r}$ & $\mathrm{r}^{2}$ \\
\hline 1 & .7552 & .5704 \\
2 & .8475 & .7183 \\
3 & .7702 & .5933 \\
4 & .8272 & .6843 \\
5 & .4856 & .2358 \\
6 & .7269 & .5283 \\
7 & .6306 & .3976 \\
8 & .7180 & .5155 \\
\hline
\end{tabular}

${ }^{*}$ All $d f=98$, all $p<.01$ 
Table 2

Correlation Matrix Showing the Extent to Which Individual Differences in Tongue Flick Rate are Reliable on a Day to Day Basis

\begin{tabular}{|c|c|c|c|c|c|c|c|c|c|c|}
\hline \multirow[b]{2}{*}{ Day } & \multicolumn{10}{|c|}{ Day } \\
\hline & 1 & 2 & 3 & 4 & 5 & 6 & 7 & 8 & 9 & 10 \\
\hline 1 & & $.9114^{*}$ & .6667 & .1958 & .0703 & .6945 & .1372 & .3205 & .0654 & .3983 \\
\hline 2 & & & $.8193^{*}$ & .3363 & .3019 & .6911 & .2360 & .4745 & .0464 & .4227 \\
\hline 3 & & & & .6876 & .5122 & $.7838^{*}$ & .6120 & $.8668^{*}$ & .4445 & .6623 \\
\hline 4 & & & & & .6386 & .5104 & $.9903^{*}$ & $.9286^{*}$ & $.7553 *$ & $.7633^{*}$ \\
\hline 5 & & & & & & .4299 & .5803 & .6149 & .1216 & .4073 \\
\hline 6 & & & & & & & .4792 & .6554 & .2278 & .6393 \\
\hline 7 & & & & & & & & $.8998^{*}$ & $.7980^{*}$ & $.7636^{*}$ \\
\hline 8 & & & & & & & & & $.7351^{*}$ & $.7507 *$ \\
\hline 9 & & & & & & & & & & .4545 \\
\hline
\end{tabular}

${ }^{*} p<.05$

Although all snakes revealed an association between tongue flick rate and square traversing rate, large individual differences were seen in the absolute levels of responsiveness. For example, the most active snake had an overall mean tongue flick rate of $25.0 / \mathrm{min}$, and the corresponding mean number of squares traversed was $11.1 / \mathrm{min}$. The least active snake had a tongue flick rate of $2.5 / \mathrm{min}$ and a square traversing rate of $.5 / \mathrm{min}$. Accordingly, we decided to determine whether or not the pattern of individual differences seen on any given day was reliable. That is, does the pattern of individual differences on Day $\mathrm{n}$ correlate with the pattern seen on Day $n+1, n+2$, etc.? Table 2 presents a complete product-moment correlation matrix wherein the eight individuals' number of tongue flicks on each day has been correlated with their number of tongue flicks on each other day. Table 3 presents the same analysis for square traversing. If individual differences are reliable, the more correlation coefficients should be significant than we could expect on the basis of chance. In Table 2, 13 correlation coefficients are statistically significant, and under the null hypothesis we should expect no more than $5 \%$ (i.e., 2.25) significant values. The observed frequency of significant coefficients is considerably greater than this expectation $\left(\chi^{2}=54.06, \mathrm{df}=1\right.$, $\mathrm{p}<.01 ; \mathrm{p}$ also less than .01 by binomial test.)
Twenty-six correlation coefficients are significant in Table 3, and this observed frequency is again greater than the expectation under the null hypothesis $\left(\chi^{2}=\right.$ $263.88, \mathrm{df}=1, \mathrm{p}<.01 ; \mathrm{p}$ is also less than .01 by binomial test).

\section{DISCUSSION}

In the undisturbed home cage, the mean rate of tongue flicking of these eight snakes during a total of $400 \mathrm{~min}$ of observation was 3.3 flicks per $\min (\mathrm{SEM}=1.15)$, and the rate of movement was extremely low (it is rare for the animal to move at all, unless food is being offered or the cage is being cleaned or other forms of disturbance occur). Hence, it is clear that tongue flick rate and rate of locomotion are greatly elevated when the animals are removed from their home cages and placed into a novel environment. This suggests that the snakes actively explore the new environment and, therefore, exhibit a degree of "curiosity" greater than that reported by Glickman and Sroges (1966). However, even if exploraton can be equated with curiosity, it must be kept in mind that Glickman and Sroges measured the behavior of animals as they examined objects placed into their home cages. It is not clear that investigation of a novel environment is based on the same processes which lead animals to examine or ignore (as was the case with their snakes) novel objects in otherwise familiar surroundings.

Perhaps the most interesting finding of this investigation is the fact that individual garter snakes differ greatly in the rate of tongue flicking and square traversing in the same test environment. This fact is made all the more meaningful in view of the reliable nature of these differences. Although the exact

Table 3

Correlation Matrix Showing the Extent to Which Individual Differences in Rate of Square Traversing are Reliable on a Day to Day Basis

\begin{tabular}{|c|c|c|c|c|c|c|c|c|c|c|}
\hline \multirow[b]{2}{*}{ Day } & \multicolumn{10}{|c|}{ Day } \\
\hline & 1 & 2 & 3 & 4 & 5 & 6 & 7 & 8 & 9 & 10 \\
\hline 1 & & $.8758^{*}$ & $.7345^{*}$ & $.7212^{*}$ & .3350 & .4151 & $.7190^{*}$ & $.7352 *$ & .6550 & .6738 \\
\hline 2 & & & $.9295^{*}$ & $.8703^{*}$ & .3304 & .4268 & $.8314^{*}$ & $.8856^{*}$ & $.7782 *$ & $.7662^{*}$ \\
\hline 3 & & & & $.9622^{*}$ & .4970 & .4464 & $.9369 *$ & $.9842 *$ & $.9125^{*}$ & $.8921 *$ \\
\hline 4 & & & & & .5971 & .4379 & $.9933^{*}$ & $.9873^{*}$ & $.9747^{*}$ & $.9712^{*}$ \\
\hline 5 & & & & & & .2838 & .6340 & .5849 & .5951 & .6858 \\
\hline 6 & & & & & & & .4430 & .4573 & .4115 & .4188 \\
\hline 7 & & & & & & & & $.9798^{*}$ & $.9774 *$ & $.9799 *$ \\
\hline 8 & & & & & & & & & $.9585^{*}$ & $.9507 *$ \\
\hline 9 & & & & & & & & & & $.9883 *$ \\
\hline
\end{tabular}

${ }^{*} p<.05$ 
degree of statistical reliability may vary from sample to sample depending upon the ranges of variation present in them, it seems justifiable to attempt an interpretation of tongue flicking and locomotion which might shed light on the meaning of these individual differences.

There is no doubt that tongue flicking is a component of exploration. There is also no doubt that locomotion and tongue flicking can be activated to different extents by different stimuli, especially foods (Burghardt, 1966, 1967a,b). However, it is not clear that stimuli which elicit high rates of tongue flicking are "preferred" stimuli. In our experience a familiar food elicits only a few tongue flicks before striking and feeding actually begin. Unfamiliar foods or environments, on the other hand, tend to elicit a lot of tongue flicking and head movement. Also, ambiguous stimuli (such as a lizard which has been rubbed with a mouse and which is then presented to a lizard-eating rattlesnake) generate much investigation. Hence, within a particular snake, high rates of tongue flicking may be a sign of stimulus ambiguity, novelty, or uncertainty, all of which place an information-processing demand on the animal.

This reasoning could be extended to the differences between individuals by suggesting that snakes which characteristically exhibit many tongue flicks are gathering more information during their examination of stimuli than individuals which emit fewer tongue flicks. However, high information need could mean two totally opposite things: (1) snakes might generate high rates of information-gathering behavior because they have difficulty with recognition and/or analysis such that redundancy is necessary; or (2) high rates of information-gathering behavior might indicate greater processing capacity (such animals could be experiencing more aspects of stimulus sources than individuals which tongue flick at lower rates). The only way to decide between these alternatives is to examine behaviors which are correlated with differences in tongue flick rate. For example, if snakes which tongue flick a lot are also rapid learners, then the second view would be supported; the first view would be supported if these snakes turned out to be slow learners.

\section{REFERENCES}

Burghardt, G. M. Stimulus control of the prey attack response in naive garter snakes. Psy chonomic Science, 1966, 4, 37-38.

Burghardt, G. M. Chemical cue preferences of inexperienced snakes: comparative aspects. Science, 1967a, 157, 718-721.

Burghardt, G. M. Chemical perception in newborn snakes. Psychology Today, 1967b, 1, 51-53.

Carr, A. F., Jr. Notes on the habits of the short-tailed snake, Stilosoma extenuatum Brown. Copeia, 1934, 3, 138-139.

Glickman, S. E., \& Sroges, R. W. Curiosity in zoo animals. Behaviour, 1966, 24, 151-188.

Noble, G. $K$. The sense organs involved in the courtship of Storeria, Thamnophis and other snakes. Bulletin of the American Museum of Natural History, 1937, 73, 673-725.

(Received for publication January 16, 1975.) 